\title{
Evolución y características de la desigualdad en México en el siglo XXI: desafíos para una nueva agenda pública*
}

\section{Evolution and characteristics of inequality in Mexico in the $21^{\text {st }}$ century:}

challenges for a new public agenda

Jesús Vaca**

Recibido: 10 de diciembre de 2019

Revisado: 25 de febrero de 2020

Aprobado: 10 de marzo de 2020

Cómo citar: Vaca, J. (2020). Evolución y características de la desigualdad en México en el siglo xxi: desafios para una nueva agenda pública. Revista CIFE: Lecturas de Economía Social, 22(37), 121-137. DoI: https://doi. org/10.15332/22484914/6043

* Universidad de Guadalajara. Licenciado en Administración y Maestro en Negocios y Estudios Económicos por la Universidad de Guadalajara.jvacamedina@gmail.com 


\section{Resumen}

Se analiza la distribución de los ingresos en México y su evolución a lo largo del siglo XXI. Se encontró que los endorements y el acervo de capital son factores determinantes para entender este fenómeno, debido a la excesiva concentración de la riqueza y a la fuerza de divergencia $(r>g)$. Este par de hechos ha ocasionado que los ingresos de la clase capitalista hayan pasado de 55\% del ingreso nacional en el 2003 a casi el 60\% entre el 2012 y el 2013. Se concluye que las estrategias de gasto social implementadas por el gobierno mexicano no han sido eficaces, debido a su poca capacidad de corregir el problema de fondo. La nueva agenda pública debe ir dirigida a reducir la brecha entre $r$ y $g$, y un esquema que comienza a difundirse son los impuestos sobre el capital y la riqueza, pero se requieren más estudios para justificar dicha estrategia.

Palabras clave: desigualdad, México, política fiscal.

Clasificación JeL: E62, H83, I14.

\section{Abstract}

The income distribution in Mexico and its evolution throughout the $21^{\text {st }}$ century are analyzed. It was found that endowments and the capital stock are determining factors to understand this phenomenon, due to the excessive concentration of wealth and the force of divergence $r>g$. These two events have caused the income of the capitalist class to have increased from $55 \%$ of the national income in 2003 to almost $60 \%$ between 2012 and 2013. It is concluded that the social spending strategies implemented by the Mexican Government have not been effective due to its poor ability to correct the underlying problem. The new public agenda should be aimed at reducing the gap between $r$ and $g$, and a scheme that begins to spread are taxes on capital and wealth, but more studies are required to justify this strategy.

Keywords: inequality, fiscal policy, Mexico.

JEL Classification: E62, H83, I14. 


\section{Introducción}

Después de un periodo de gran crecimiento económico en México durante el inicio de la segunda mitad del siglo $\mathrm{xx}$, la fuerte volatilidad y la crisis de la deuda de la década de los años 80 ocasionaron la reestructuración del modelo económico. Este cambio de paradigma dio paso a una época de crecimiento sostenido y de mayor estabilidad, pese a que las tasas fueron significativamente menores a las alcanzadas en el periodo anterior.

El crecimiento sostenido y la estabilidad macroeconómica provocaron que el sector privado se convirtiera en el motor de la economía nacional al promover la inversión por la vía de la certidumbre y las expectativas favorables en el corto y largo plazo. Por otro lado, también redujeron la presión del sector público al contener la volatilidad de las principales variables macroeconómicas como la inflación y el tipo de cambio. Los resultados de este nuevo esquema de organización de los mercados es lo que Esquivel (2010) llama el estancamiento estabilizador.

Ante esta situación, las políticas de los últimos gobiernos han sido dirigidas a alcanzar mayores tasas de crecimiento económico. Esto ocasionó que se perdiera el enfoque en otros problemas que se desarrollaban en el seno de la nación como la desigualdad en la distribución de los ingresos y de la riqueza. Recientemente, se ha observado que la derrama generada por el crecimiento económico se destina a una minoría, fenómeno que también se presenta en varios países alrededor del mundo ${ }^{1}$.

Como consecuencia de esto, el Gobierno mexicano muestra cada vez mayor interés en combatir la pobreza y la desigualdad, pero lamentablemente los esfuerzos no han sido efectivos. Prueba de ello es que, pese al fuerte aumento del gasto social, los indicadores que miden estos fenómenos casi no han mostrado cambios, e incluso algunas veces han empeorado.

Es por esta razón que el actual documento tiene como primera meta presentar un análisis exhaustivo de México respecto a la evolución de la desigualdad, con la finalidad de conocer realmente la situación actual y de encontrar las principales causas de este fenómeno. Posteriormente, se realiza una evaluación minuciosa de lo que ha hecho el Estado recientemente para determinar si las estrategias implementadas están en línea con las causas detectadas. Por último, el objetivo final es, con base en la información generada, discutir una nueva agenda pública que debería seguir el Gobierno mexicano para llevar a cabo políticas que impacten significativamente en la erradicación de la desigualdad en nuestro país. 
Se piensa que el sistema implementado en la actualidad, basado en programas y transferencias sociales para fortalecer la demanda de los deciles inferiores, no ha funcionado para atacar el problema de fondo, sino simplemente para administrarlo. Esto ha derivado en cifras que reflejan un escenario ficticio de lo que realmente sucede en el contexto nacional.

La importancia de regresar la desigualdad a un rol central de los estudios económicos no es solamente su afectación sobre el sentimiento de justicia social, sino que también existe evidencia que demuestra la relación entre este fenómeno y el crecimiento económico, tanto por el lado de la oferta como de la demanda.

Es por estas razones que se requiere la urgente implementación de políticas adecuadas por parte de los Estados para su regulación, con lo que se pretende impedir que los mercados se adueñen de los mecanismos de distribución y evitar, de este modo, la evolución de la desigualdad como se ve hoy en día. Solo de esta manera se podrá crear una armonía entre la justicia social y el progreso económico.

Para el desarrollo de estos puntos, el artículo se divide de la siguiente manera, luego de esta introducción: en el segundo apartado se muestra la situación actual de nuestro país en materia de desigualdad y concentración de los ingresos, a la vez que se analizan las principales causas de la evolución de este fenómeno; en la tercera sección se estudian las políticas implementadas por el Gobierno mexicano en los últimos años, a la vez que se proponen nuevos esquemas de trabajo a manera de una nueva agenda pública para erradicar la desigualdad desde sus orígenes; por último, se discuten algunas conclusiones y se abordan los temas que deberán ser objeto de estudio en los próximos años en relación con el vínculo entre política fiscal y desigualdad social.

\section{Orígenes de la desigualdad en el siglo XXI}

En México, el debate sobre la distribución de los ingresos y la riqueza ha ido en aumento, tanto en el ámbito político como académico. Lamentablemente, el volumen de estudios científicos avanza a un ritmo mucho menor que las discusiones cotidianas o políticas. Sin duda, esta tendencia se debe a la fuerte polarización de la desigualdad en nuestro país. Prueba de ello es que, según datos de González y Vargas (2014), el 48\% de la población mexicana vive en condiciones de pobreza, mientras otro $10 \%$ se encuentra en riesgo de caer en la misma situación. Es decir, prácticamente el 60\% de los mexicanos padece las carencias económicas y sociales que los clasifica oficialmente como pobres.

Estas cifras hacen gran contraste con los niveles de riqueza de un sector muy reducido de la población, lo cual queda evidenciado en los registros de las listas de personas más 
ricas del mundo 2 . Por ejemplo, según datos de la revista Forbes (con sus limitaciones que casi siempre conllevan a resultados subestimados), las 37 familias más ricas de nuestro país poseen un patrimonio de aproximadamente 200000 millones de dólares, es decir, casi lo equivalente al 20\% del producto interno bruto (PIB) nacional de 2016.

A la luz de estos datos, es evidente que la desigualdad en México alcanza niveles extremos, siendo uno de los principales problemas y malestares sociales de nuestro país. Siempre que la desigualdad llega a niveles críticos, la facilidad para que los ricos secuestren las instituciones y decisiones económicas y políticas es cada vez mayor, lo que priva al resto de la sociedad de un sinfín de oportunidades para mejorar su nivel y calidad de vida. De esta manera, se cae en un círculo vicioso del cual no es posible salir sin la intervención del Estado.

Sin embargo, para que el Estado intervenga con políticas adecuadas y haga frente a la desigualdad desde sus orígenes, es indispensable que se conozcan los factores que causan este fenómeno, de tal manera que se implementen estrategias que favorezcan la justicia social afectando lo menos posible la eficiencia de los mercados. Por ello, se requiere una evaluación actual para entender los factores económicos, culturales y sociales que están empujando la evolución de la desigualdad.

En este trabajo se proponen dos factores. El primero, con fundamento en las bases teóricas de Acemoglu y Robinson (2013), está relacionado con la existencia de instituciones económicas y políticas extractivas. Según Deaton (2015), la esencia de la desigualdad puede generar círculos virtuosos a través del incentivo al esfuerzo y la productividad; sin embargo, la democracia y la igualdad política son esenciales para que estos principios se cumplan a través de los mercados.

Cuando los ricos son tan ricos que se apoderan de las instituciones tanto económicas como políticas, eliminan toda opción de crecimiento para los de abajo. La desigualdad amenaza la democracia que los mercados requieren para la justa distribución de los recursos, por lo que la falta de pluralidad y expectativas, derivada de la ausencia de incentivos económicos y la escasez de oportunidades, condena a una sociedad a un círculo vicioso que puede llegar a perpetuar la desigualdad.

Según esta lógica, la transición hacia una sociedad más justa e inclusiva comienza con la apertura y la transparencia de sus instituciones políticas, lo que incentivará al surgimiento de instituciones económicas inclusivas. Cuando este par de entes propician la democracia y la igualdad de oportunidades, se inicia el camino hacia una sociedad con

2 Pese a tratarse de listados informales que no tienen fundamento en cifras oficiales, representan una herramienta útil para aproximarnos a la realidad. La subjetividad de estos documentos invita a tomarlos, en el peor de los casos, como un piso mínimo, ya que los datos se obtienen de fuentes públicas y muchas veces se ignoran fuentes de riqueza que no están a la luz de la sociedad (cuentas bancarias en paraísos fiscales, propiedades de empresas dificiles de detectar, valor de inmuebles donde radican, etc.). 
una repartición más justa de los ingresos y de la riqueza, más productiva y más rica. Solamente de esta manera podrían converger la justicia y la prosperidad.

El segundo factor, con fundamento en las bases teóricas y empíricas de Piketty (2014), es el fenómeno denominado por el mismo autor como la fuerza de divergencia $r>g$. Esta relación asume que el rendimiento del capital es superior al crecimiento de la economía, por lo que los ricos tienden a ser más ricos a través del tiempo simplemente porque iniciaron su camino siendo ricos.

Vale la pena mencionar que en el desarrollo de este documento se le presta mayor atención a este factor por dos razones: 1) es la causa y principal fuente de evolución de la desigualdad en este siglo xxI, el cual se caracteriza por el retorno de las ideas neoclásicas bajo los modelos neoliberales, y 2) la polarización a través de las instituciones extractivas es una consecuencia de la fuerza de divergencia $r>g$, por lo que es esta relación la que alimenta dichas instituciones, ya que los ricos buscan la manera de acrecentar la brecha para garantizar su posición y la de sus familias por mucho tiempo, sin importar los daños que ocasionen al resto de las personas.

¿Por qué se piensa que esta relación juega un papel tan importante en la creciente desigualdad? Básicamente, porque sociedades que funcionen bajo esta fuerza observan cómo los dueños del capital, cuyo acervo ha sido generado históricamente por generaciones previas, multiplican su riqueza a una velocidad muy superior a la cual el resto de las personas puede incrementar sus ingresos como remuneración laboral. En este sentido, es claro que la existencia de esta fuerza de divergencia atenta contra la justicia, así como contra los incentivos y la productividad, al mismo tiempo que acrecienta la brecha desigualitaria.

Esta fuerza, que el mismo Piketty (2014) cataloga como una evidencia histórica más que una relación lógica, se fortalece con las características actuales de los mercados financieros. Los endowments juegan un papel cada vez más determinante debido al acceso a mejores oportunidades de inversión, sin la limitante territorial, como consecuencia de la integración económica mundial impulsada por la globalización y los avances en las tecnologías de la información.

La reducción de riesgos de los portafolios más prominentes fomenta la polarización, ya que aumentan la probabilidad de que una persona que nace en los percentiles superiores de la distribución del ingreso muera en la misma clase social, independientemente de su productividad, preparación y esfuerzo. Asimismo, reduce la probabilidad de que una persona sin una dotación inicial muy grande pueda escalar a los percentiles más altos como fruto de su trabajo y dedicación.

Este hecho ha perjudicado negativamente la idea muy difundida en la actualidad sobre la preparación académica y profesional y su impacto en el nivel de vida de una persona 
a través de mejores oportunidades de empleo. La desigualdad en el siglo XXI suele beneficiar más al capital que a la formación y al talento.

Para ilustrar estos conceptos, en el caso mexicano se obtuvieron los datos de INEGI (2017) y de Vaca (2017), los cuales cubren el periodo 2004-2013. El rendimiento promedio del capital $(r)$ de estos 10 años fue de $15.6 \%$, mientras que el crecimiento total promedio $(g)$, que incluye tanto el crecimiento económico como el demográfico ${ }^{3}$, fue de $3.9 \%$. Si colocamos estos valores sobre las variables de la fuerza de divergencia, es fácil concluir que el capitalista promedio en México requiere ahorrar únicamente el 25\% de sus ingresos para que su patrimonio aumente a la misma velocidad a la que una persona promedio que vive de su trabajo aumenta los suyos. En el caso de que la clase capitalista como un todo ahorre una proporción mayor al 25\% de sus ingresos, será inevitable la evolución de la brecha desigualitaria entre capitalistas y trabajadores. La tabla 1 refleja el desglose de estas cifras, año tras año desde 2004 hasta 2013.

Tabla 1. Desigualdad $r>g$ en México (2004-2013)

\begin{tabular}{|cccccc|}
\hline Año & $\boldsymbol{r}(\%)$ & $\begin{array}{c}\text { Crecimiento } \\
\text { económico }\end{array}$ & $\begin{array}{c}\text { Crecimiento } \\
\text { demográfico }\end{array}$ & $\begin{array}{c}\text { Crecimiento } \\
\text { total }\end{array}$ & $\boldsymbol{r - g ( \% )}$ \\
\hline 2004 & 21.89 & 4.21 & 1.18 & 5.39 & 16.50 \\
\hline 2005 & 18.44 & 3.07 & 1.13 & 4.21 & 14.24 \\
\hline 2006 & 19.58 & 4.98 & 1.17 & 6.15 & 13.43 \\
\hline 2007 & 16.97 & 3.22 & 1.27 & 4.50 & 12.48 \\
\hline 2008 & 16.37 & 1.38 & 1.38 & 2.75 & 13.61 \\
\hline 2009 & 12.46 & -4.74 & 1.40 & -3.35 & 15.81 \\
\hline 2010 & 14.64 & 5.20 & 1.24 & 6.44 & 8.20 \\
\hline 2011 & 12.68 & 3.92 & 1.25 & 5.17 & 7.51 \\
\hline 2012 & 11.60 & 4.03 & 1.19 & 5.21 & 6.39 \\
\hline 2013 & 11.36 & 1.44 & 1.15 & 2.58 & 8.77 \\
\hline
\end{tabular}

Fuente: elaboración propia con datos obtenidos de INEGI (2017) y Vaca (2017).

3 El crecimiento demográfico (asumiendo una tasa de crecimiento similar entre clases sociales) suma al crecimiento total porque reduce el peso de los endowments y reduce el peso de la riqueza generada históricamente. Por ejemplo, una herencia tiene menor peso cuando se divide entre cuatro hijos que cuando se transfiere a un hijo único. 
Este fenómeno ha ocasionado que los ingresos por capital (variable denominada por la letra $a$ en este documento), entendidos como la renta obtenida por la clase capitalista como fruto del rendimiento de sus activos, absorban proporciones cada vez mayores del ingreso nacional. De esta manera, la clase capitalista - que, como se vio al inicio de la sección, es una minoría y asunto del cual se profundizará más adelante- obtiene una porción cada vez mayor del crecimiento de la economía mexicana.

Por otro lado, la tabla 2 contiene los datos de la variable $a$, la cual es construida con el ratio ingresos por capital/ingreso nacional, para el periodo 2003-2013. Ante la evidente tendencia al alza de esta variable en el siglo Xxi, solamente hace contraste la notoria caída en el 2009, que tiene su origen en la crisis financiera mundial que ese año golpeó a México. Sin embargo, resalta la rápida recuperación que tuvieron las grandes empresas de un año a otro, lo que se debe en gran medida al apoyo que recibieron por parte del Gobierno mexicano, con la finalidad de contener la inminente crisis debido al desempleo y la fuga de capitales.

Además, se puede concluir que, en los próximos años, según la tendencia mostrada en los resultados de la tabla 2, la clase capitalista llegará al umbral del 60\% del ingreso total, mientras la gran masa trabajadora tendrá que conformarse con la repartición del $40 \%$ restante.

Tabla 2. Ingresos de capital como proporción del ingreso nacional

\begin{tabular}{|ll|}
\hline Año & $\boldsymbol{a}(\%)$ \\
\hline 2003 & 55.33 \\
\hline 2004 & 57.63 \\
\hline 2005 & 58.10 \\
\hline 2006 & 59.23 \\
\hline 2007 & 59.43 \\
\hline 2008 & 59.96 \\
\hline 2009 & 56.39 \\
\hline 2010 & 58.46 \\
\hline 2011 & 59.46 \\
\hline 2012 & 59.55 \\
\hline 2013 & 58.29 \\
\hline
\end{tabular}

Fuente: elaboración propia con datos obtenidos de INEGI (2017). 
Ahora bien, estas cifras por sí solas no dicen nada. En realidad, no son un buen fundamento para afirmar la existencia de un problema, y mucho menos para asegurar que tiene afectaciones negativas sobre la vida de las personas. En esencia, como ya se dijo, la concentración de los ingresos en la clase capitalista está fuertemente vinculada con las economías capitalistas como una evidencia histórica.

El grave problema social inicia cuando se combina este fenómeno con una sociedad con altos niveles de concentración del capital y de la riqueza. Cuando sucede así, la minoría poseedora de los activos es aquella que absorbe la mayor proporción de los ingresos, originando el círculo vicioso de la desigualdad.

Lamentablemente, la información respecto a la distribución de la riqueza en México es muy escasa, lo cual limita en gran medida los estudios en este campo. Pese a estas dificultades, según datos del Sistema de Cuentas Nacionales de México ${ }^{4}$, presentados por el Instituto Nacional de Estadística y Geografia (INEGI, 2017), el valor de la riqueza nacional para el 2003 ascendía a 17 billones de pesos, mientras que para el 2013 era de aproximadamente 67 billones de pesos; es decir, se multiplicó por cuatro en 10 años. En contraste con estas cifras, en este mismo periodo la economía mexicana creció a una tasa de $2.67 \%$ anual.

Para suplir las falencias de las cuentas nacionales, se recurrió a fuentes no oficiales para aproximar los niveles de concentración. Con apoyo de instituciones y firmas privadas, cuyas mediciones no son formales como Forbes y Credit Suisse, principalmente, en Vaca (2017) se presentan las siguientes cifras para el 2012: el 0.003\% de la población adulta posee el $9 \%$ de la riqueza nacional; avanzando un poco en la distribución, se estima que el $0.18 \%$ de los mexicanos posee el $18 \%$ de la riqueza. Con estos números, es racional pensar que el $1 \%$ de la población es dueña de prácticamente el $90 \%$ de la riqueza, y que gran parte de los activos nacionales es propiedad del $10 \%$ más rico.

Con la información disponible en este documento se demuestra que prácticamente el $10 \%$ de la población, decil que concentra aproximadamente el $90 \%$ de la riqueza de nuestro país, absorbe cerca del $60 \%$ del ingreso nacional. El 40\% restante se reparte en el mercado laboral ${ }^{5}$ mediante los ingresos por trabajo.

Tomando en cuenta estos datos, y bajo un análisis con el panorama completo, se comprueba la excesiva desigualdad que existe en nuestro país, así como la existencia de las condiciones económicas para que siga evolucionando a través del tiempo. La fuerza de divergencia $r>g$, así como la concentración de la riqueza, reforzará de manera

4 Para mayor información respecto las fuentes y metodología de las cuentas nacionales de México utilizadas, consulte INEGI (2014).

5 Los ingresos por trabajo también presentan grandes brechas de desigualdad dentro de este; sin embargo, en este trabajo se asume la clase trabajadora como un todo. Trabajos futuros deberán estudiar las causas de los orígenes y la evolución de la desigualdad en el mercado laboral. 
automática este fenómeno y el círculo vicioso que genera, tal como ha sucedido en los últimos años. Todo parece indicar que se detendrá hasta que el Gobierno tenga la capacidad de atacarlo desde la raíz.

En la tabla 3 se presenta la evolución de la desigualdad y de la concentración de los ingresos totales en nuestro país (sin hacer diferenciación entre ingresos por capital e ingresos por trabajo) de 2004 a $2012^{6}$, con la intención de mostrar que en ese periodo el 10\% más rico del país se ha hecho más rico gracias a que el $50 \%$ más pobre es aún más pobre. Esto se refleja en que la clase media ha permanecido casi igual en estos años.

Tabla 3. Distribución del ingreso nacional total 2004-2012

\begin{tabular}{|lccccc|}
\hline $\begin{array}{l}\text { Proporción de la } \\
\text { Población }\end{array}$ & \multicolumn{5}{c}{ Participación en el ingreso nacional (\%) } \\
\hline \\
\hline $10 \%$ más rico & $\mathbf{2 0 0 4}$ & $\mathbf{2 0 0 6}$ & $\mathbf{2 0 0 8}$ & $\mathbf{2 0 1 0}$ & $\mathbf{2 0 1 2}$ \\
\hline $40 \%$ del medio & 62.07 & 61.15 & 63.76 & 63.54 & 64.28 \\
\hline $50 \%$ más pobre & 61.07 & 30.94 & 30.60 & 30.72 & 30.25 \\
\hline
\end{tabular}

Fuente: elaboración propia con datos de INEGI (2017) y de INEGI (2013).

Por otro lado, esta tabla también refleja que los factores mencionados previamente han ocasionado un deterioro en la distribución total de los ingresos, favoreciendo claramente a los más ricos, mientras que las estrategias de los gobiernos no han sido efectivas para erradicar, o por lo menos reducir, la concentración.

Por último, este conjunto de tablas y de cifras fortalece la conclusión y apoya la hipótesis en relación con las causas del origen y la evolución de la desigualdad en México en el siglo xxi. La extrema concentración de la riqueza, aunada a la presencia de la relación $r>g$, ocasiona que los ingresos se concentren cada vez más en la exclusiva clase capitalista.

Este hecho debe llevar a que las nuevas agendas públicas replanteen su perspectiva de análisis estratégico. Según las condiciones de este nuevo mundo y los mecanismos con

6 Para más información respecto a la metodología empleada para la obtención de dichos resultados, consúltese Vaca (2017). 
los que operan los mercados, la distribución de los ingresos debe contemplarse desde un enfoque funcional más que personal, es decir, entre clases sociales, entre capitalistas y trabajadores.

\section{Política fiscal y reducción de la desigualdad}

En la última década, la discusión sobre los alcances del actuar gubernamental en la desigualdad en la distribución de los ingresos ha tomado gran interés, tanto en el ámbito político como en el académico. No obstante, son más las discusiones cotidianas y políticas rodeadas de ambigüedades y creencias que las reflexiones más formalizadas y estructuradas en el ámbito académico. Aunque - también hay que decirlo - es de gran ayuda saber la relevancia social que tiene este tema.

En ambos contextos, la política fiscal ha sido concebida y aceptada como la mejor y la más poderosa arma con la que cuenta un Estado para incidir en la economía. Gran parte de este hecho se debe a la asignación casi completa de la política monetaria a los bancos centrales, cuyo principal objetivo es contener la inflación y mantener el nivel de precios. Esta imputación surgió como consecuencia de los graves problemas inflacionarios que vivió una gran cantidad de países alrededor del mundo desarrollado entre 1970 y 1980, y que se prolongó en el mundo subdesarrollado hasta la década de $1990^{7}$.

Parte del cambio de paradigma económico de las décadas de 1970 y 1980, en el que entra el llamado modelo neoliberal, implicó la exclusión del Estado de un sinfín de actividades económicas, dando paso a mercados más libres y abiertos con el exterior. El Estado, a través del gasto público y de los impuestos como principales herramientas de la política fiscal, tendría como objetivo combatir los diferentes fallos de mercado, entre los que destaca la distribución de los ingresos.

En este punto existe un consenso generalizado, soportado por fundamentos teóricos y empíricos con gran validez, sobre el mayor alcance e incidencia del gasto público en la distribución de los ingresos. Además, hay muchos casos de éxito en los que el gasto público, a través de transferencias y programas sociales, ha logrado reducir los niveles de desigualdad de un país.

Por ejemplo, Nuti (2011) asume que prácticamente todo el gasto público debe asignarse como gasto social, de tal manera que las obras de inversión pública se minimicen al máximo. Con esto, los gobiernos destinarían mayor cantidad de recurso público a la conservación del empleo a través de la subvención al consumo de los deciles de menores ingresos (transferencias, subsidios, pensiones, etc.), lo que reduciría la brecha entre 
pobres y ricos. Loaiza (2012), Perrotini (2004) y Palley (2004) abordan el mismo fenómeno y llegan a conclusiones similares, todos desde un enfoque postkeynesiano.

Sin embargo, Romero (2014) concluye que el destino y la calidad del gasto juegan un papel muy importante según la perspectiva con la que se analice la distribución de los ingresos. Por un lado, demuestra que el gasto público impacta de manera positiva en la distribución personal de los ingresos, además de incentivar el crecimiento económico, tanto por el lado de la oferta como de la demanda. Por otro lado, sugiere prestar atención a las clasificaciones del gasto, ya que encuentra evidencia de que el gasto de capital impacta significativamente a la distribución funcional, mientras que el gasto social únicamente tiene injerencia en la distribución personal.

Pese a la evidencia existente, parece que la estrategia implementada en la actualidad no ha tenido los resultados esperados, tal vez debido a sesgos en el enfoque de análisis. Como se vio en la sección anterior, la pobreza y la desigualdad en México han incrementado constantemente en el transcurso del siglo XXI, al mismo tiempo que el gasto social se ha incrementado un $70 \%$ desde el 2000. Además, la desigualdad a nivel mundial también se ha hecho más extrema, lo que se refleja en una mayor participación del decil $\mathrm{x}$ en el ingreso nacional desde la década de 1980 (Ampudia, 2015).

La difusión de estas nuevas cifras a nivel mundial ocasionó el renacimiento del debate acerca del alcance de la política fiscal en la distribución de los ingresos. Una de las principales corrientes en las que ha devenido esta discusión es la incidencia de los impuestos en este fenómeno. En este contexto, Ampudia (2015) reconoce que el impacto de la política de impuestos es mucho más amplio de lo que comúnmente se piensa.

Un documento que apoya esta tendencia es el de Crudu (2015). En su trabajo, el autor estudia el impacto de los impuestos directos en la evolución de la desigualdad en la distribución personal de los ingresos en los países de la Unión Europea. Demuestra que tanto el gasto público como los impuestos son herramientas eficientes para reducir los niveles de desigualdad, pero observa que el alcance de los impuestos rebasa a los efectos del gasto público.

Por ello, es urgente seguir desarrollando nuevos documentos que analicen el alcance de las políticas tributarias sobre la desigualdad en el siglo XXI, con todos los factores que la caracterizan. Solo de esta manera se tendrá la capacidad de determinar las mejores estrategias gubernamentales para erradicar, y no solamente administrar, la desigualdad.

En este sentido, Piketty (2014), quien analiza la desigualdad en la distribución de los ingresos desde un enfoque funcional, retoma una idea clásica iniciada a mediados del siglo pasado por Kalecki, en la que se utilizan los impuestos, principalmente sobre el acervo de capital, como mecanismos de redistribución. El autor hace énfasis en el éxito que tuvieron algunas sociedades capitalistas bajo este esquema en su lucha contra la 
desigualdad (sobre todo eran impuestos sobre las herencias y las sucesiones), pero que hoy en día se han dejado en el olvido.

La lógica de regresar a un modelo en el que se grava a los patrimonios radica en atacar el problema desde la raíz, y no solo implementar estrategias que, además de no haber surtido los efectos esperados, dañan las finanzas públicas y ponen en riesgo la soberanía nacional a causa del endeudamiento.

Las cifras presentadas en la sección anterior fortalecen la hipótesis de la fuerza de divergencia $r>g$ como una de las principales causas de la evolución de la desigualdad en México en el siglo XXI ${ }^{8}$. Este fenómeno se refuerza por el poder que esta concentración otorga a la clase alta, lo que atenta contra la democracia y la justicia a causa del secuestro de las instituciones económicas y políticas, reduciendo así las oportunidades de éxito del resto de la población. Debido a este proceso, la desigualdad se convierte en un círculo vicioso que tiende a concentrar cada vez más la riqueza y los ingresos en una minoría.

La implementación de un conjunto de impuestos que graven los activos impactaría directamente la variable $r$, ya que reduciría el rendimiento neto del capital y con ello la diferencia entre $r$ y $g$, con lo que la evolución de la brecha desigualitaria sería menor. Además, este mecanismo dotaría al Estado de mayores recursos para asignar a proyectos de inversión y de gasto social que beneficien a los deciles inferiores. De esta manera, el Estado puede conducir la economía a un círculo virtuoso, a través del efecto crowding in y del incremento en la productividad por las crecientes oportunidades de desarrollo y el fortalecimiento de la demanda agregada.

Además, parte de las ventajas de un modelo de impuestos a la riqueza es la facilidad de definición, de medición y de monitoreo de los activos (Piketty, 2015a). Estas bondades hacen de este sistema un mecanismo más progresivo y eficiente contra la desigualdad, para que los ricos contribuyan al bien común.

Wisniewski (2010) hace un análisis en retrospectiva, y asegura que, si Kalecki hubiera sido contemporáneo a nosotros, la primera medida que sugeriría a los gobiernos del mundo sería gravar el capital e invertir en infraestructura. Apostaría por el gasto de capital, más que por el gasto social, debido a la concepción de la distribución funcional de los ingresos, por lo que la política keynesiana de déficit para estimular la demanda no sería de gran ayuda en la actualidad, como se ha reflejado recientemente.

La dinámica de los mercados actuales y el mayor impacto de las tecnologías en la producción hacen que esta idea tome aún más fuerza. Brynjolfsson y McAfee (2011)

8 En el trabajo de Piketty (2014), se detalla de manera minuciosa esta misma conclusión para una muestra más grande de países. 
encuentran que esta tendencia ha desequilibrado el reparto entre capital y trabajo en las sociedades modernas a favor del primero, debido a que las empresas invierten más en capital y menos en trabajo.

Ante esta nueva corriente, han surgido varios documentos que enriquecen la discusión y permiten seguir trabajando en la formación de una nueva agenda pública. Entre ellos destaca el de Fujita (2015), en el cual se sostiene que hay una lógica pérdida en la fuerza de divergencia $r>g$ desde su concepción, ya que el valor de $r$, entendido como el rendimiento del acervo total de riqueza de un país, asume que "todo" el capital es empleado en el proceso productivo de la economía, lo cual dista mucho de ser real.

Por ese motivo, para hacer un análisis oportuno de esta relación que lleve a la adecuada toma de decisiones es indispensable dividir al acervo nacional en dos categorías: el capital real (aquel que es empleado en el proceso productivo) y el capital financiero (aquel que no es utilizado en ningún proceso productivo). Obviamente, la estrategia de los impuestos sobre la riqueza tendría que ir dirigida a los activos que son productivos y que se convierten de algún modo en ingresos para su dueño.

Otra aportación relevante es la de López-Bernardo, López-Martínez y Stockhammer (2016). Este trabajo sostiene que la principal deficiencia para el cálculo de la relación $r>g$ es la metodología, ya que la productividad marginal de los factores se obtiene a través de una función de producción Cobb-Douglas. Al utilizar esta herramienta, además de cometer el mismo error mencionado en Fujita (2015), asume que todos los activos obtienen la misma tasa de rendimiento, algo totalmente fuera de sentido, sobre todo en este siglo XXI caracterizado por la dominancia de mercados globales y abiertos.

En realidad - sostiene el mismo trabajo - las condiciones actuales han conducido a economías multisector, y cada uno de estos sectores tiene tasas de rendimiento muy diferentes en función de las características de los mercados. Incluso dentro de los mismos sectores existen varios tipos de activos, y cada uno de ellos suele tener una rentabilidad diferente al resto.

Es por esta razón que la riqueza no se utiliza en lo mismo ni se multiplica a la misma velocidad. Por ello, la existencia de un impuesto sobre el capital no debería tener cuidado únicamente con gravar los activos que efectivamente son empleados en los procesos productivos, sino que también tendría que prestar atención al tipo de activo que se está gravando. Un descuido de este tipo podría conducir a sociedades aún más desigualitarias, ya que favorecería a aquellas personas que posean activos cuyo rendimiento esté por encima del promedio, a saber, del valor de $r$.

En pocos años, los avances al respecto son considerables. Sin embargo, pese a estos estudios y los avances logrados, no se encontró ningún documento cuyo objetivo sea comparar la eficiencia de la política tributaria versus la política de gasto público para 
incidir en la distribución funcional de los ingresos. Lógicamente, tampoco hay nada que compare la eficiencia de políticas de impuestos sobre el capital versus políticas de gasto.

Hoy en día, Crudu (2015) sugiere que es indispensable que surjan nuevos estudios que relacionen el impacto de la política económica en la distribución de los ingresos. Esto es fundamental para avanzar en la construcción de la nueva agenda pública que permita al Gobierno mexicano, y a otros países, estructurar estrategias adecuadas para combatir la desigualdad y lograr la unión entre la justicia social y el progreso económico.

\section{Conclusiones}

En tiempos recientes, México ha sufrido un aumento constante en los niveles de desigualdad, al tiempo que ha incrementado a un ritmo nunca antes visto el gasto público destinado a corregir dicho fenómeno. Esto ha conducido al país a una situación doblemente peligrosa: por un lado, la riqueza y los ingresos se concentran cada vez en menos manos; por el otro, los niveles de deuda pública han alcanzado cifras históricas, lo cual amenaza las finanzas públicas y la soberanía nacional.

Con base en los datos presentados en este trabajo, se puede argumentar que la principal causa de los orígenes y la evolución de la desigualdad en la distribución de los ingresos en México es la fuerza de divergencia $r>g$, así como la consecuente acumulación de poder en la élite que los lleva a apropiarse de las instituciones económicas y políticas, reduciendo (y a veces eliminando) el acceso a las oportunidades de crecimiento y desarrollo del resto de la población. Esto conduce a la sociedad a un círculo vicioso de desigualdad creciente, del cual no se puede escapar sin la intervención oportuna del Estado.

Este hecho rompe el paradigma respecto a la visión de la distribución de los ingresos, ya que se debe pasar de un enfoque personal a funcional, es decir, entre clases sociales. Por este motivo, el gasto público, pese a ser la herramienta comúnmente aceptada para combatir la desigualdad, no ha hecho más que administrar el problema sin atacarlo desde la raíz.

En este sentido, ha surgido una corriente, impulsada por Piketty (2014), que busca la renovación de un modelo clásico propuesto por Kalecki: un impuesto progresivo sobre el capital. Según el cambio de paradigma, la política tributaria, específicamente sobre la riqueza, tiene la capacidad de corregir el problema desde sus orígenes. La nueva agenda pública debe girar hacia esta estrategia si se quiere tener un país que armonice la relación entre justicia social y progreso económico.

El principal inconveniente que observa Piketty (2015b) para la instauración de un nuevo modelo en el que la democracia recupere el control de los mercados, y con ello la 
promoción de instituciones políticas y económicas inclusivas, es que el interés privado, quien tiene un gran poder de influencia sobre los tomadores de decisiones, siempre justificará la permanencia del modelo actual con cuestiones de eficiencia, aunque esto no coincida con el interés general.

Aún falta mucho camino por recorrer, pues se requiere de discusiones más rigurosas para impulsar la política tributaria como un instrumento eficiente contra la desigualdad. Por ello, es necesario que nuevos documentos estudien los alcances y limitantes de la política tributaria en la distribución funcional de los ingresos.

\section{Referencias}

Acemoglu, D., \& Robinson, J. (2013). Por qué fracasan los países. México: Crítica.

Ampudia, N. (2015). Trends in income distribution and the influence of fiscal policy. XIV International Business and Economy Conference, Bangkok, Thailand.

Brynjolfsson, E., \& McAfee, A. (2011). Race against the machine. Lexington: Digital Frontier Press.

Crudu, R. (2015). The influence of fiscal policy on income inequality in european union's member states. Business Systems and Economics, 5(1), 46-60. DOI: https://doi. org/10.13165/VSE-15-5-1-05

Deaton, A. (2015). El gran escape. México: Fondo de Cultura Económica.

Esquivel, G. (2010). De la inestabilidad macroeconómica al estancamiento estabilizador. En N. Lustig (Ed.), Crecimiento Económico y Equidad (pp. 35-78). México D.F.: Colegio de México.

Fujita, T. (2015). Missing equation in Piketty's r-g theory. Economics and Business Letters, 4(2), 57-62. Dor: https://doi.org/10.17811/ebl.4.2.2015.57-62

González, R. y Vargas, R. (2014). Pobreza en México: aún elevada pese a avances en los últimos años: FMI. La jornada en línea.

Instituto Nacional de Estadística y Geografía (INEGI). (2017). Banco de Información Económica, Sistema de Cuentas Nacionales de México. Recuperado de https://www.inegi. org.mx/sistemas/bie/. 
Instituto Nacional de Estadística y Geografía (INEGI). (2014), Sistema de Cuentas Nacionales de México: cuentas por sectores institucionales 2003-2013: año base 2008: fuentes y metodología. México, Instituto Nacional de Estadística y Geografía.

Instituto Nacional de Estadística y Geografía (INEGI). (2013). Encuesta Nacional de Ingresos y Gastos de los Hogares (2004-2012). Recuperado de https://www.inegi.org.mx/ programas/enigh/tradicional/2012/

Loaiza, O. (2012). La demanda agregada y la distribución del ingreso: Un estudio a partir de los modelos de crecimiento kaleckianos. Cuadernos de Economía, 31(58), 23-47.

López-Bernardo, J., López-Martínez, F., \& Stockhammer, E. (2016). A post-keynesian response to Piketty's "fundamental contradiction of capitalism". Review of Political Economy, 28(2), 190-204. DOI: https://doi.org/10.1080/09538259.2015.1060057

Nuti, D. (2011). El ciclo político de kalecki desde una óptica actual. Revista de Economía Crítica, 2(12), 207-213.

Palley, T. (2004). From keynesianism to neo-liberalism: Shifting paradigms in economics, 20-29; en D. Johnston, \& A. Saad-Filho (Eds.), Neoliberalism - a critical reader. Londres: Pluto Press.

Piketty, T. (2014). El capital en el siglo XXI. México: Fondo de Cultura Económica.

Piketty, T. (2015a). Capital, inequality and power. Fournal of Ethnographic Theory, 5(1), 517 527. DOI: http://dx.doi.org/10.14318/hau5.1.027

Piketty, T. (2015b). Capital and wealth taxation in the $21^{\text {st }}$ century. National Tax Fournal, 68(2), 449-458. DOI: http://dx.doi.org/10.17310/ntj.2015.2.10

Perrotini, I. (2004). Restricciones estructurales del crecimiento en México, 1980-2003. Economía UNAM, 1(1), 86-100.

Romero, I. (2014). Income distribution and macroeconomic theories of growth. Negotium, 29(10), 56-78.

Vaca, J. (2017). Pobreza y desigualdad en el México del siglo XXI. Capitalismo neoliberal y libre mercado. México: Universidad de Guadalajara.

Wisniewski, M. (7 de noviembre de 2010). Michael kalecki: La crisis se lee con "K". La fornada. Recuperado de https://bit.ly/2ZBMLKH 